\title{
The Influence of Cyclic Stress History on the Energy Absorption of Weathered Rock
}

\author{
Nurul Ainain Mohd Salim*, Zainab Mohamed \\ Faculty of Civil Engineering, Universiti Teknologi MARA (MARA University of Technology), Shah Alam, Selangor, Malaysia
}

Received January 30, 2021; Revised July 27, 2021; Accepted August 9, 2021

\section{Cite This Paper in the following Citation Styles}

(a): [1] Nurul Ainain Mohd Salim, Zainab Mohamed, "The Influence of Cyclic Stress History on the Energy Absorption of Weathered Rock," Civil Engineering and Architecture, Vol. 9, No. 5A, pp. 41 - 46, 2021. DOI: 10.13189/cea.2021.091305.

(b): Nurul Ainain Mohd Salim, Zainab Mohamed (2021). The Influence of Cyclic Stress History on the Energy Absorption of Weathered Rock. Civil Engineering and Architecture, 9(5A), 41 - 46. DOI: 10.13189/cea.2021.091305.

Copyright $@ 2021$ by authors, all rights reserved. Authors agree that this article remains permanently open access under the terms of the Creative Commons Attribution License 4.0 International License

\begin{abstract}
Energy absorption plays an important role in rock deformation and rock failure. Under compression load, rock fails abruptly which can cause sudden energy release that demonstrates the structural failure. The deformation of rock is based on the energy absorption and dissipation which is found dissimilar for each weathered specimen. Weathered granite namely Grade II, III and IV were tested under static compression load to determine the energy accumulation and dissipation of weathered rock is determined. The results were then compared to rock samples with and without pre-loaded cyclic stress. The comparison is made in order to observe the effect of cyclic stress history on weathered granite samples. Based on the result, it is demonstrated that the weathered granite samples with cyclic stress history absorbed more energy as compared to the samples without preloaded cyclic stress.
\end{abstract}

Keywords Energy Absorption, Energy Dissipation, Weathered Rock, Cyclic Load

\section{Introduction}

Weathered rock is non-homogeneous material which has pre-existing cracks and flaws due to tropical weathering [1]. When an external load is applied on the rock, the rock starts to deform [2]. The mechanical energy applied by the external load and the thermal energy are continuously converted into internal energy of rock. Therefore, the specimen internal energy increases and gradually the material constituents fragmented up from its original stable state. As the external load increase, the specimen stretches to its critical state and eventually the micro cracks are distributed. Beyond the critical state, the macro cracks intensely causing the rock to fail abruptly. The elastic potential energy accumulated in the rock is release and changed into a new stable state with low internal energy which is named as residual strength of the specimen.

Lately, the study on energy is becoming a new outlook for rock breakage analysis. According to [3], the energy absorption of porous rock is under impact loading. [4] has studied the energy dissipation mechanism and produced damage model of failure under triaxial loading of marble. However, it is revealed that post-failure behaviour of rocks completely depends on the cyclic loading path and the amount of energy absorbed by the rock under tensile stress [5]. The energy evolution of rock under cyclic loading has been investigated by many researchers and they found that the total absorbed energy mostly transforms into elastic energy. The remainder of stored energy is released in the form of dissipated hysteresis energy for the microcrack propagation and coalescence as stated in [6].

According to [7] who studied the mechanism of rock fatigue damage and the energy absorption from the cyclic stress-strain curve, the brittle hard rocks undergo fatigue cracking when subjected to cyclic loading. The post-cyclic behavior of rock was determined by subjecting the specimen under cyclic load. The specimen that survived the $10^{6}$ cycles was then tested under static uniaxial 
compression. During the progressive uniaxial loading, the rock specimen will experience compaction of existing crack at initial load; subsequently the elastic deformation, pre-peak plastic deformation, post peak softening and finally residual deformation will occur. The energy absorbed and energy dissipated by the specimen differs at each phase where it is closely related to the fracture pattern of the specimen. The cracks were favorably propagated through the rock matrix rather than inside the grains (Transgranular cracks) when subjected to cyclic loading [6]. They also mentioned that cyclic loading resulted in predominantly intergranular fracturing compared to transgranular fracturing. On the contrarily, under static uniaxial compression, the energy is mainly elastic potential energy and specimen dissipated energy.

\subsection{Energy Behaviour of Rock Specimen}

Under the uniaxial compression strength test, the energy absorbed by the rock specimen is equal to the work done on the specimen, when some of the energy absorbed is stored as elastic potential energy and some is dissipated in generating the plastic deformation, acoustic emission, and the rise in the specimen temperature. Upon unloading, the elastic potential energy reduces the specimen deformation. Reloading path is assumed to correspond with the discharging path in complete stress-strain curve with that the elastic potential energy at any point of the curve can be calculated according to the stress value of the point and also the pre-peak elastic modulus. Through rock stress-strain curves, the quantity of energy released from each rock specimen differs. The more energy is absorbed by a rock specimen, the more rock fragments will be produced. In this case, different weathering grade also resulted in varying type of rock fragment.

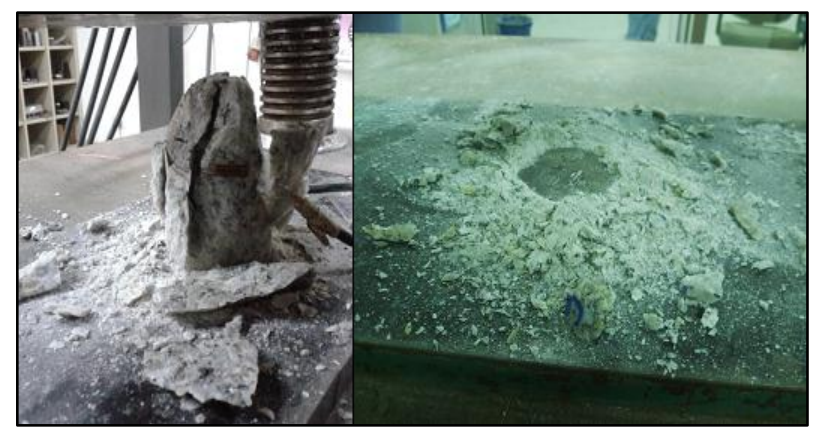

Figure 1. Typical Fatigue Failure of Granite Specimen

Investigations revealed that softening post-failure behaviour of rocks completely depends on the cyclic loading path and energy amount absorbed in rocks [5]. They also explained from the emerging of new micro cracks and modes of rock breakage. Under cyclic loading, the closed micro cracks are re-opened when the stress is induced repeatedly on the crack surface and reach its critical level. The damages on rock specimens are more noticeable as the plastic strain accumulates during loading.
As a result, rock specimens produced more dust and fine-grain fragmentation of rocks under cyclic loading after failure as shown in Figure 1. It is shows that the continuous plastic strain accumulated during the loading and therefore the damages are more noticeable. It acts as evidence that the cyclic loading would cause more damages and fragmentation than static loading.

The rock energy behavior is derived from the thermodynamic theory [2]. They had illustrated the accumulation and dissipation of energy under static uniaxial compression load as shown in Figure 2. The energy absorbed by the specimen is mainly consumed for friction loss between mineral particles as well as the expansion of primary microcracks and the initiation of new cracks. Nevertheless, energy dissipation continually damages the internal microscopic structure of rock, which will deteriorate the rock strength and eventually complete structural failure. If the stresses induce micro-fracturing but not failure, then the mechanical properties of the rock may vary significantly from point to point depending on the local stress history [8].

Thus, this paper aims to study the effect of cyclic stress history on rock energy behavior by subjecting the rock specimens under cyclic loading. Rock specimens experienced 1 million cycles without failure with the frequency of $1 \mathrm{~Hz}$ is then tested for uniaxial compression load. This is what know specimen with cyclic stress history. The energy behavior was measured under the static uniaxial stress-strain curve. The energy dissipation, energy release and the growth of micro cracks were analyzed throughout the deformation and failure progression.

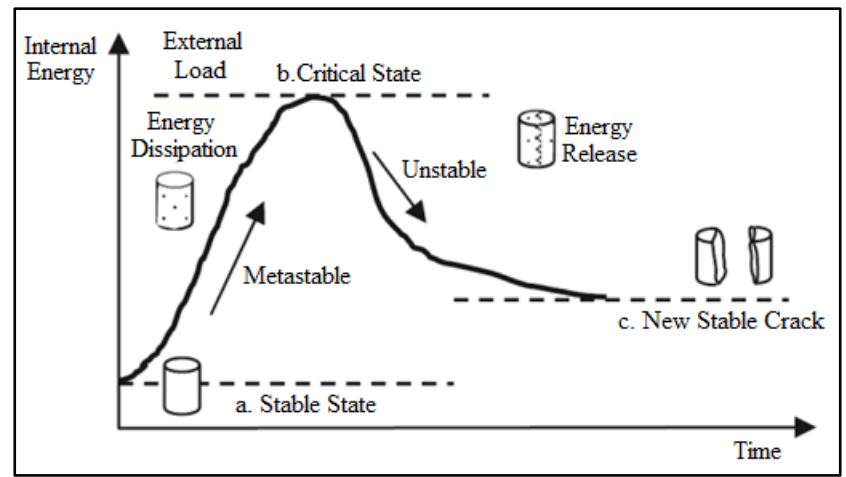

Figure 2. Thermodynamic Change during Rock Deformation and Failure (Modified from [2])

\section{Materials and Methods}

The cylindrical rock specimens with height to diameter ratio of 2 and a diameter of $\pm 55 \mathrm{~mm}$ were prepared as specified in [8]. The tropically weathered granite rocks ranged from slightly weathered to highly weathered were sampled (Grade II, Grade III and Grade IV). The weathering grades of rock specimen were classified by rebound hardness number according to the classification 
by [10]. The cyclic loading test was conducted on the specimens by using a closed-loop servo-hydraulic IPC-1000 Universal Testing Machine with $1000 \mathrm{kN}$ capacity. The cyclic sinusoidal load was applied on the rock specimens at a frequency set at $1 \mathrm{~Hz}$ and stress level of $0.7 \sigma_{\mathrm{c}}$ under constant cyclic loading. The ratio of minimum to maximum stress (stress ratio) was controlled at 0.17 . This is to control the data inconsistency between the specimens weathering grades. The applied cycling load was limited to one million cycles by adopting the previous similar studies recommended. The specimens were also furnished with two strain gauges to record the specimen external axial strain and radial strain. The test setup is illustrated as in Figure 3.

Before the cyclic loading tests, the physical and mechanical properties of the rocks were measured as shown in Table 1. The uniaxial compression test on rock samples were conducted to obtain the minimum and maximum strength of rock under static loading condition and to provide a reference for subsequent cyclic loading tests.

\section{Result and Discussion}

The experimental work has determined the behavior of elastic potential energy under uniaxial compression cyclic load and discussed as follows.

The laboratory testing produced a graphical plot of stress-strain curve. From the stress-strain curve of each weathered specimen, the absorbed energy per unit volume is calculated which is equal to the area of the region under the stress-strain curve to the horizontal axis. The empirical equation used to determine the energy absorption is comes from the explicit mathematical equation of energy per unit volume as defined by [11] as below:

$$
\mathrm{W}_{1}=\int \sigma_{1} \mathrm{~d} \varepsilon_{1}=\Sigma 1 / 2\left(\sigma_{i}+\sigma_{i-1}\right)\left(\varepsilon_{i}-\varepsilon_{i-1}\right)
$$

The elastic potential energy, $\mathrm{W}_{t}$ equals half of $\sigma_{1} \mathrm{~d} \varepsilon_{1}$, where $\sigma_{i}$ and $\varepsilon_{i}$ is the value of stress and strain at point $i$ respectively under the complete stress-strain curve. The initial value of each stress and strain is equals to zero. The elastic strain, $\varepsilon_{t}$ is needed for storing the elastic energy in rock specimen; the recoverable elastic strain, $\sigma_{1}$ is divided by modulus of elasticity, E. Thus, the elastic potential energy becomes:

$$
\mathrm{W}_{t}=\sigma_{1}^{2} / 2 \mathrm{E}
$$

The energy dissipation, $\mathrm{W}_{\mathrm{s}}$ of rock specimen is the difference between the total energy absorbed, $\mathrm{W}_{1}$ and the stored elastic potential energy, $\mathrm{W}_{t}$, where the unit is in $\mathrm{MJ} / \mathrm{m}^{3}$ and $\mathrm{m}^{3}$ is equivalent to unit stress written in parenthesis. Therefore, for every stress-strain curve of each specimen, the total absorbed energy and the stored elastic potential energy was calculated as shown in Figure 4 to Figure 9. The energy behavior of weathered rock specimens before and after pre-loaded cyclic stress were analyzed and compared. In figure 4 to figure 9 shows four different curves denoted as axial stress to axial strain (1), absorbed energy to axial strain (2), elastic potential energy to axial strain (3) and the last curve represents the energy dissipation to axial strain (4). In the figure (graph), the symbol $a$ represents the initial loading of specimens without preloaded cyclic stress while $a^{\prime}$ for sample with preloaded cyclic stress.

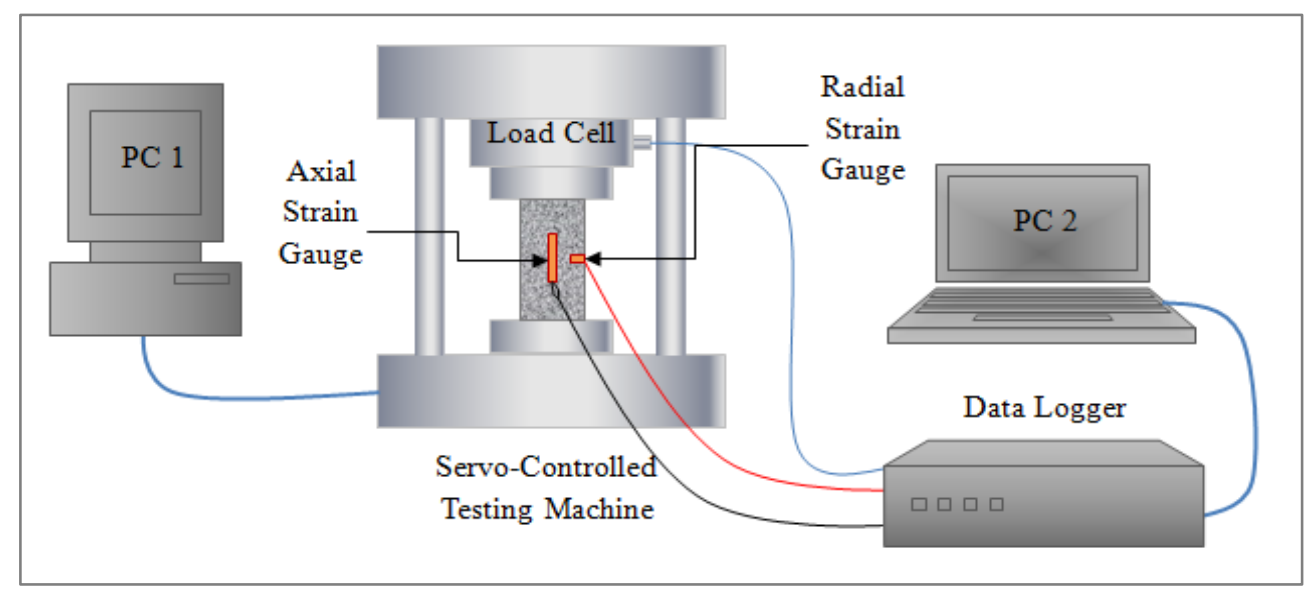

Figure 3. Uniaxial Compression Cyclic Load Test Setup

Table 1. Physical and Mechanical Properties of Rock Samples

\begin{tabular}{|c|c|c|c|c|c|c|c|}
\hline \multirow{2}{*}{$\begin{array}{c}\text { Rock } \\
\text { Type }\end{array}$} & \multirow{2}{*}{$\begin{array}{c}\text { Weathering } \\
\text { Grade }\end{array}$} & \multirow{2}{*}{$\begin{array}{c}\text { No. of } \\
\text { Specimen }\end{array}$} & & \multicolumn{5}{|c|}{$\begin{array}{c}\text { Rebound } \\
\text { No. (R) }\end{array}$} & $\begin{array}{c}\text { Moisture } \\
\text { Content (\%) }\end{array}$ & Porosity (\%) & UCS (MPa) & \multirow{2}{*}{$\mathbf{V}_{\mathbf{p}}(\mathbf{m} / \mathbf{s})$} \\
\hline \multirow{3}{*}{ Granite } & II & 10 & 46 & 0.116 & 0.889 & 112.9 & 4982 \\
\cline { 2 - 9 } & III & 10 & 36 & 0.306 & 0.899 & 42.3 & 3633 \\
\cline { 2 - 8 } & IV & 10 & 17 & 1.345 & 0.904 & 13.6 & 1478 \\
\hline
\end{tabular}




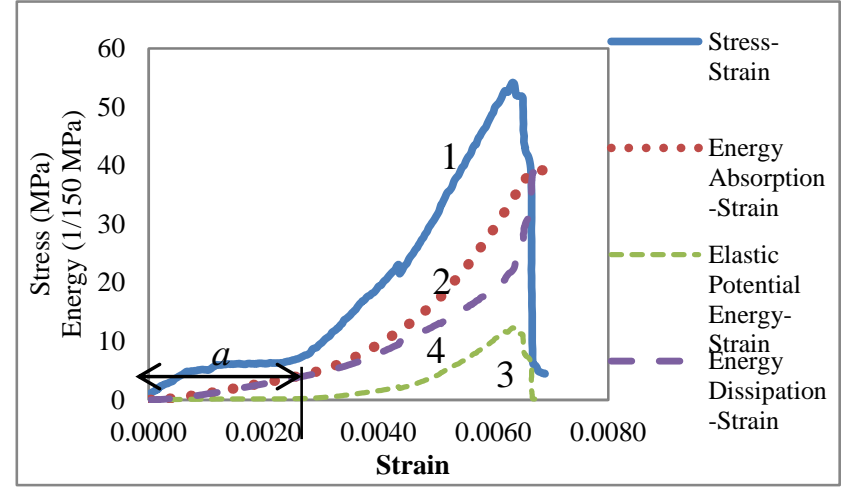

Figure 4. Energy Behaviour of Granite (GII) without Cyclic Stress History

For slight weathered granite (GII), Figure 4 shows the stress-strain curve without cyclic stress history. The graph shows that during the closing of initial cracks, approximately $18 \%$ of the absorbed energy is transformed into elastic potential energy, as the axial stress increases the transform ratio increases and at the peak point ratio is up to $61 \%$. There is no post peak residual elastic energy is observed. Instead, the dissipated energy is found to be very small during the initial loading, and significantly increases during the propagation of microcrack towards breakage. As the stress dip abruptly, the accumulated elastic potential energy is released promptly causing rock specimens failed as brittle material.

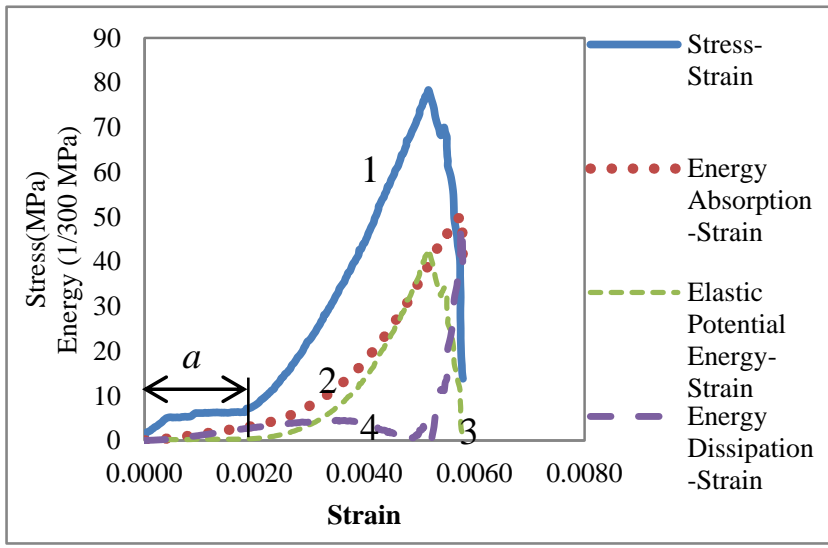

Figure 5. Energy Behaviour of Granite (GII) with Cyclic Stress History

However, Figure 5 shows GII granite with pre-loaded cyclic stress. At the early stage of crack closure, about $63 \%$ of the absorbed energy is transformed into elastic potential energy and just before failure the absorbed energy mounts up to $68 \%$. At the peak point, the ratio of elastic energy to total absorbed energy decreased to $90 \%$ because of the energy has dissipated in plastic deformation and the residual elastic energy becomes $8.8 \%$ of the absorbed energy.

Figure 6 shows the Grade III specimen without cyclic stress history. At the closing of initial cracks, about $16 \%$ of the absorbed energy is converted into elastic potential energy; subsequently with the increase in axial stress, the percentage increase is $89 \%$ at the peak. The post peak residual elastic energy only accounts for $1.7 \%$ of the total absorbed energy which indicating the elastic energy lost is believed to transform into kinetic energy which caused the plastic deformation.

Consequently, Grade III specimen with cyclic stress history (Figure 7) shows about 22\% of the absorbed energy in specimen is changed into elastic potential energy where the total absorbed energy rose to $92 \%$ at peak point.

Another comparative analysis on Grade IV specimens is shown as in Figure 8 and Figure 9. Evidence concluded that the Grade IV specimen without cyclic stress history consumed approximately $11 \%$ of the absorbed energy into elastic potential energy and ratio increases up to $94 \%$ at peak. Comparatively the same weathering grade specimen with cyclic stress consumed 18\% of the absorbed energy into elastic potential energy where the total absorbed energy increases up to $93 \%$. The energy dissipation on the specimens only differs by $7 \%$, however the post-peak energy dissipation has rose to $82 \%$ of the absorbed energy.

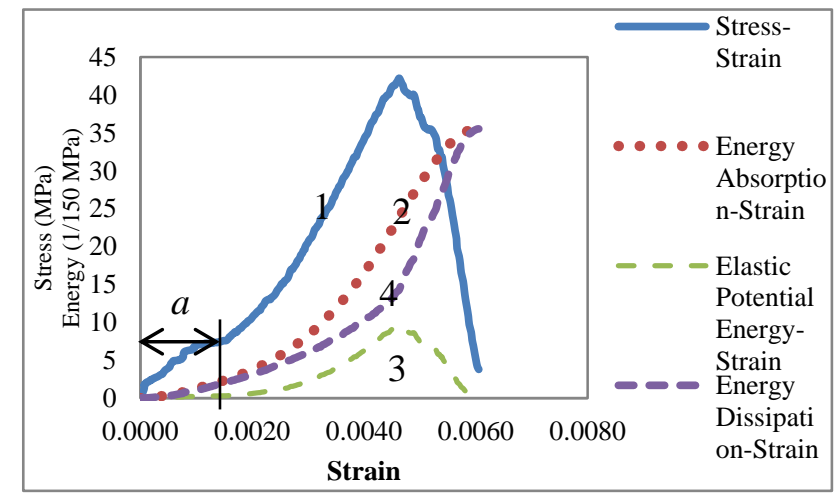

Figure 6. Energy behaviour of granite (GIII) without cyclic stress history

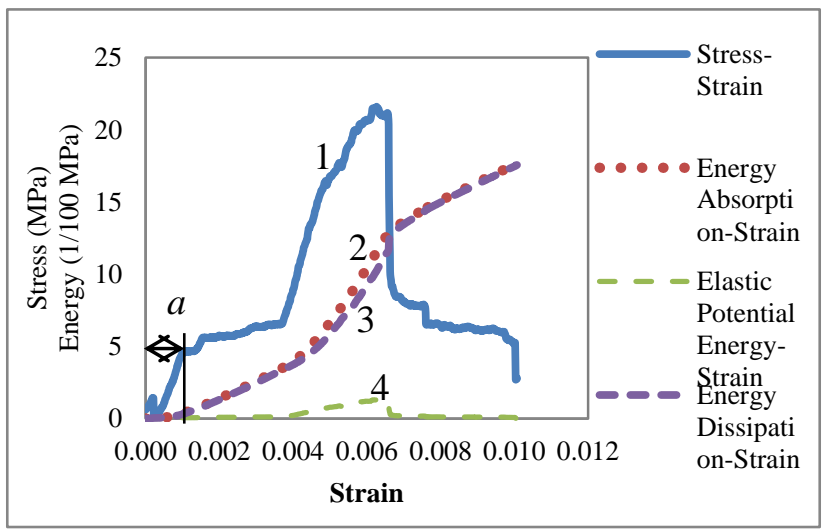

Figure 7. Energy behaviour of granite (GIII) with cyclic stress history 


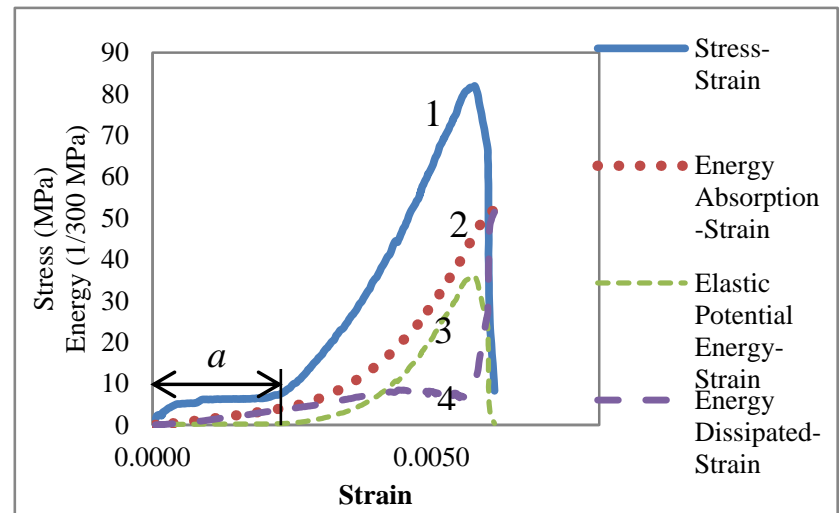

Figure 8. Energy behaviour of granite (GIV) without cyclic stress history

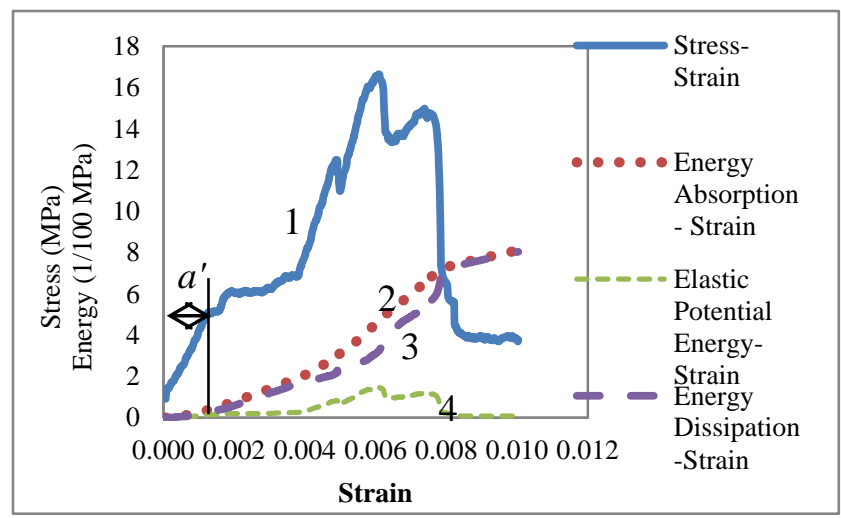

Figure 9. Energy behaviour of granite (GIV) with cyclic stress history

Based on the test results, comparatively the curve gradient measured from initial stage of loading to the elastic stage (marked as $a$ for specimens without preloaded cyclic stress while $a$ ' for preloaded cyclic stress) is steeper when compared to specimens without cyclic stress history. Regarding the time taken, Grade II specimens is 0.1 times faster as compared to the specimen without pre-loaded cyclic stress. For Grade III specimen, the time taken is 1.184 and Grade IV is 0.1 faster as compared to the specimen without pre-loaded cyclic stress. The cyclic stress history has also influenced the time taken during the closing of the pre-existing microcrack in specimens. Therefore, the weathered rock specimen experiencing stress history will deform sooner. The densification of weathered rock specimen increases its stiffness hence the micro-fracturing stage accelerates sooner than expected. The stress history has also affected the reduction in rock strength. This evidence was observed on slightly weathered to highly weathered granite (Grade II, Grade III and Grade IV).

\section{Conclusions}

This study discussed the work carried out on weathered granite. It shows that the weathered granite specimens with cyclic stress history absorbed more energy as compared to specimens with no preloaded cyclic stress. Energy absorption of weathered specimen is also found to be dependent on the degree of rock weathering. The Grade IV granite absorbed less energy comparatively to slightly weathered granite (Grade II) and moderately weathered granite (Grade III) rocks. At the pre peak zone, all the weathered specimens experienced a little dissipation of energy. At the peak of the curve, the ratio of elastic energy stored in weathered specimen to the total absorbed energy has reached maximum value. The sudden released of energy resulted in the rocks burst phenomena especially for Grade II and Grade IIII specimens.

The experimental study showed that even though the cyclic load was set at low stress ratio, the reduction in rock strength was observed for Grade II, Grade III and Grade IV specimen indicated that the cyclic stress history contributed to the degradation of the specimen. The high and prolong cyclic loading has caused rapid deformation of weathered rocks especially at the transition of initial loading to the elastic region of the stress-strain curve. The stress cycles applied induced the redistribution of grain and micro cracks which then the sample became more compacted and denser. It was also found that the cyclic loading test on weathered granite appeared to be sensitive to specimen geometry, mineralogy and texture.

\section{Acknowledgments}

The authors wished the appreciation to Universiti Teknologi MARA and Ministry of Higher Education, Malaysia for funding this study and providing the support facilities.

\section{REFERENCES}

[1] Z. Mohamed, A. G, Rafek, I. Komoo. Characterisation and Classification of the Physical Deterioration of Tropically Weathered Kenny Hill Rock for Civil Works. Electronic Journal of Geotechnical Engineering. Volume 12A, 2007.

[2] M. Kwasniewski. Mechanical behaviour of rocks under true triaxial compression - A review, in: True triaxial testing of rocks, edited by M. Kwasniewski, X, Li, and M, Takahashi, Chapter 8, Geomechanics Research Series 4, CRC Press, Taylor \& Francis Group, Leiden Holland, 99-138, 2012.

[3] L. Huang, W. Shi. Energy absorbing of porous rock investigated under impact loading. Electronic Journal of Geotechnical Engineering (EJGE), 37-44, 2013.

[4] L. Zhang, M. Ren, S. Ma, Z. Mang. Energy dissipation mechanism and damage model of marble failure under two stress paths, Frattura ed Integrita Strutturale, 30: 515-525, 2014.

[5] M. Ghamgosar, P. Stewart, N. Erarslan. Investigation the 
Effect of Cyclic Loading on Fracture Propagation in Rocks by Using Computed Tomography (CT) Techniques, American Rock Mechanics Association, 1-5, 2015.

[6] Y. Zhou, D. Zhao, Q. Tang, M. Wang. Experimental and numerical investigation of the fatigue behaviour and crack evolution mechanism of granite under ultra-high-frequency loading. R. Soc. open sci., 2020.

[7] E. Eberhardt, D. Stead, B. Stimpson. Identifying crack initiation and propagation thresholds in brittle rock, Canada Geotechnical Journal, 35, 222-233, 1998.

[8] N. Erarslan, D.J. Williams. Mechanism of rock fatigue damage in terms of fracturing modes. International Journal of Fatigue, 43: 76-89, 2012.
[9] ISRM, The Complete ISRM Suggested Methods for Rock Characterization, Testing and Monitoring: 1974-2006. Suggested Methods Prepared by the Commission on Testing Methods, International Society for Rock Mechanics, Compilation Arranged by the ISRM Turkish National Group Ankara, Turkey, 628, 2007.

[10] E. W. Brand, H.B Phillipson. Site investigation and geotechnical engineering practice in Hong Kong. Geotechnical Engineering, 15, 97-153, 1984.

[11] L. Han, Y. He, G. Xu. Analysis of energy dissipation and load carrying capacity of rock during experiment, Mining Science and Technology-Wang, Ge \& Guo (Eds), 433-436, 2004. 